\title{
How Transit Agencies Implement Best Practice Strategies in Complementary ADA Paratransit Eligibility
}

\author{
Molly E. Ranahan, Jordana L. Maisel, and James A. Lenker \\ University at Buffalo
}

\begin{abstract}
To encourage greater fixed route transit use for people with disabilities, transit agencies are implementing more rigorous paratransit eligibility determination practices. Previous studies identified best practice strategies for eligibility determination, but did not fully document the implementation of these strategies, nor the factors contributing to successes or challenges. This study interviewed 16 transit agencies across the United States to investigate the use of ADA complementary paratransit eligibility best practices in order to (a) determine the extent to which transit agencies are adopting suggested best practices as part of determining paratransit eligibility, (b) describe how agencies apply these strategies in daily operations, and (c) explore factors that contribute to implementation successes and challenges. Findings indicate that many transit agencies have incorporated multiple best practice eligibility strategies as part of department-wide changes in paratransit operations and have overcome implementation challenges by recognizing departmental limitations and collaborating with other departments and organizations.
\end{abstract}

Keywords: paratransit eligibility determination, ADA complementary paratransit, fixed route transit

\section{Introduction}

Paratransit services provide a vital link to community activities by providing transportation to doctors' offices, religious activities, and employment for many individuals with inadequate access to transportation. For people who are unable to use fixed route public transportation, paratransit provides a demand responsive option. In contrast with fixed route, paratransit trips often provide curb-to-curb service that picks up riders at their home and drops them off at their destination, or vice versa. Title II of the Americans with Disabilities Act (ADA) requires public transit authorities to maintain complementary paratransit services to areas within a 3/4 mile distance from fixed route bus lines and rail stations. To prevent discriminatory practices, Title II also requires that the fare for ADA complementary paratransit rides not exceed twice the amount charged for a comparable trip on fixed route service (Gupta et al. 2010; Henning 2007).

(C) 2018 Molly E. Ranahan, Jordana L. Maisel, and James A. Lenker

https//doi.org/10.5038/2375-0901.21.2.5

ISSN: 1077-291X | Licenced under Creative Commons License Attribution - Noncommercial 4.0

The Journal of Public Transportation is published by the Center for Urban Transportation Research at the University of South Florida 
Despite limitations, such as advanced scheduling requirements, frequent delays, and cancellation penalties, paratransit demand increased substantially between 2007 and 2010 (GAO 2012). During this time, the 10 largest transit agencies experienced a $22 \%$ increase in registered paratransit riders, a $27 \%$ increase in the number of riders taking at least one paratransit trip per year, and a 31\% increase in the overall number of paratransit trips. These agencies reported various reasons for this growth, including reduced availability of other transportation services, the growing population of older adults, inaccessible transit stops and pedestrian infrastructure, inexperience traveling by public transportation for individuals with disabilities, and challenges among transit agencies implementing effective ADA paratransit eligibility determination processes.

With paratransit's growing popularity, transit agencies are experiencing challenges balancing the physical and economic demands of providing ADA complementary services and accessible fixed route services. Agencies continue to face increasing pressure to contain paratransit costs while maintaining service quality (Gupta et al. 2010). The average paratransit trip costs transit operators $\$ 29.30$, which is 3.5 times more expensive than the cost-per-trip for fixed route transit. Between 2007 and 2010, the overall cost of providing paratransit increased $10 \%$ due to rising fuel, insurance, and maintenance costs, as well as increased ridership. By 2030, the annual funding for paratransit is expected to grow by $\$ 3.3$ billion for operating expenses and $\$ 598$ million for capital costs (Koffman et al. 2010).

All stakeholders benefit from shifting paratransit ridership to fixed route options. For paratransit riders, it leads to increased flexibility and personal independence. For transit agencies, advantages include cost containment. But despite these benefits, limited research has explored the implementation of best practice strategies for encouraging able paratransit riders to use fixed route options.

\section{Literature Review}

\section{Addressing Operational Challenges}

The Federal Transit Administration (FTA) requires agencies to self-certify compliance with ADA paratransit service requirements in order to receive funding. Since the FTA selects only a few agencies for a full review each year, identifying the specific actions agencies take to address changes in cost and ridership remains difficult. To investigate these issues, the US Government Accountability Office (GAO) conducted a national study using the FTA's ADA compliance reports, a generalizable web-based survey of 145 transit agencies, and interviews with federal officials and 20 transit agencies. Study findings revealed that to offset rising paratransit trips and costs transit agencies pursue more accurate eligibility determinations, align paratransit service with ADA requirements, offer travel training, collaborate with health and human service professionals and other transportation providers, improve the accessibility of fixed route service, and implement new technology for scheduling and dispatch (GAO 2012).

A more recent study conducted by Thatcher et al. (2013) describes the areas of operation where public transportation agencies have implemented changes and improvements to encourage greater fixed route transit use by people with disabilities, including (1) bus stops; (2) marketing, public information, and travel training; (3) fare incentives; (4) transit service; and (5) ADA paratransit eligibility criteria. These findings reinforce previous research (Hoesch and Roszner 1995; Weiner 1998, 2007; Mathias and Thatcher 2002; Welch and Dubost 2005; Rogers and Wiemiller 2006; Cross 2007; National Academies 2007; Sapper, Goodwill, and Carapella 2009; NCD 2005) that illustrates the importance of agency eligibility determination practices in addressing operational challenges. A 2009 study funded by the US Department of Transportation (USDOT) and Florida Department of Transportation further supports this and classifies more rigorous eligibility practices as the best means to address heightened cost and demand (Sapper 2009). 


\section{A Focus on Eligibility}

Public transit agencies that offer ADA paratransit services are required to institute a practice for verifying the complementary ADA paratransit eligibility of their customers ( 49 CFR $\$ \$ 37.125,37.127$ ). Eligibility criteria, defined by the laws and regulations issued by USDOT, prevent complementary paratransit from becoming the primary transportation service for people with disabilities. Although the USDOT ADA legislation does not mandate the use of an explicit eligibility determination process (49 CFR $\$ 37.123$ [e]), ADA regulations do specify criteria for the complementary ADA paratransit service and regulations for trip-by-trip eligibility. Based on these regulations, agencies develop three common types of ADA paratransit eligibility: (1) Unconditional eligibility, granted to persons who are not able to use fixed route transit services under any conditions; (2) Conditional eligibility, granted to persons who are able to use fixed route transit services some of the time under certain conditions; and (3) Temporary eligibility, granted to persons whose disability or health condition is expected to last less than the standard term of eligibility (Thatcher et al. 2013).

Transit operators have reshaped eligibility application and decision-making practices over the past 20 years. Agencies previously depended on applicant self-certification to determine eligibility, a strategy focused on determining individuals' inability to use public transit. Many agencies now focus on identifying applicants' abilities to use fixed route service, and instead frequently implement other screening methods including in-person interviews and functional, cognitive, and visual ability assessments. Research within the last 10 years also suggests the value of more rigorous eligibility determinations on ADA paratransit demand. Through a survey of national transit agencies and follow-up interviews with representatives, Sapper et al. (2009) reported that $33 \%$ of agencies use in-person interviews with all applicants and $19 \%$ implement functional assessments, with a greater number of agencies using these strategies on an as-needed basis. TCRP Report 119 (National Academies 2007) found that agencies that use trip-by-trip eligibility screening experience $48 \%$ lower complementary ADA paratransit demand than agencies that do not.

Thatcher et al. (2013) used an extensive literature review and a national survey of transit agencies to identify eligibility determination best practice strategies for complementary ADA paratransit providers. These strategies included (1) using in-person interviews and functional assessments; (2) establishing and enforcing measurable and specific eligibility conditions, such as actual weather conditions; (3) developing efforts to improve passenger awareness about conditions of eligibility and other transportation options; (4) using detailed on-street assessments to detect path-of-travel barriers; (5) offering travel training on fixed route for conditionally eligible passengers; and (6) adopting trip-by-trip eligibility and software to enforce it. However, this study was limited to only case studies of agencies that adopted these best practice strategies and therefore did not fully document the implementation of these strategies. Moreover, it did not explore the factors that contribute to implementation successes or challenges.

In response to the aforementioned gaps, the current study interviewed transit agencies to investigate the use of paratransit eligibility best practices, as defined by Thatcher et al. (2013), from initial application and assessments procedures to scheduling and trip-by-trip decision making. The research goals were to (a) determine the extent to which transit agencies are adopting suggested best practices as part of determining the complementary ADA paratransit eligibility of customers, (b) describe how agencies implement these strategies in daily operations, and $(c)$ explore factors that contribute to implementation successes and challenges.

\section{Methods}

The emergence of complementary ADA paratransit eligibility best practices to promote the use of fixed route transit by people with disabilities, as well as minimal research examining the implementation of these strategies 
by paratransit agencies, suggested the need for an exploratory research design. The overall research strategy mimics the "practice-based evidence" approach used by rehabilitation researchers to obtain data and insights about everyday practices within disciplines that lack strict guidelines or standards of practice. Representatives from transit agencies across the country were interviewed in order to learn more about their paratransit practices.

The targeted sample included the 20 transit operators reported in a recent paratransit study (GAO 2012). These officials were selected based on geographic diversity (two transit authorities from each of the FTA's 10 regions), size of paratransit system, and reputation. All 20 were contacted for potential participation in this study. Prior to data collection, study approval was obtained from the Social and Behavioral Science Institutional Review Board at the University at Buffalo. Participants were not compensated for their time.

The interview questions were developed in a multistep process. The research team conducted preliminary interviews with 10 of the 20 transit agencies using an initial interview guide that aimed to identify strategies used by transit agencies to address rising costs and encourage paratransit riders to use fixed route. Midway through the interviews, the research team learned of a newly released report published by the Transportation Research Board (TRB) that outlined best practice strategies to encourage and support conditionally eligible paratransit passengers to use fixed route transportation. To avoid duplicate efforts, the research team consulted with the authors of the TRB report and determined that a follow-up study with a larger sample would address their case study limitations.

The research team then refined the interview guide so it asked transit agencies about the adoption and implementation of eligibility determination best practice strategies. Interviews with the remaining agencies and follow-up interviews with the first 10 agencies used the revised guide. A copy of the interview questions is available upon request from the first author. All interviews took place via a web-based telephone conferencing service. Each interview was audio-recorded. Verbal consent to participate was formally obtained from all participants. The second author led all phone interviews and read the scripted questions. At least one additional co-author was present for all interviews. Each member of the research team was free to interject spontaneous follow-up questions as appropriate. The interviews lasted approximately one hour. The audio recordings were subsequently transcribed by a third-party service. To ensure data integrity, the transcriptions were reviewed for accuracy by the co-authors.

Data analysis was conducted by the three co-authors, whose backgrounds collectively include urban planning, human factors engineering, occupational therapy, and outcomes research involving people with disabilities. Data analysis procedures followed three steps: (1) open coding of the data by each of the three coders in order to identify common patterns and primary coding categories; (2) refinement of thematic categories into focused clusters based on consensus among coders; and (3) thematic coding of raw data using coding categories and sub-categories (Morgan 1997). Responses were also coded for incidence density, i.e., the number of times that a theme arose. For each interview question, coders made cross-interview comparisons of participant comments, identified emergent themes, and shared interpretations via weekly meetings that occurred over a twomonth period. Accuracy and credibility of interpretations were enhanced in two ways: (a) initial respondents had the opportunity to review transcriptions of their comments and preliminary analysis, and (b) the three coders represent diverse professional perspectives, reducing the risks for biases reflecting person-specific and discipline-specific characteristics. After numerous team discussions that were interspersed with periods of individual analysis, the three coders achieved consensus in their thematic assignment of data. To facilitate replication of group findings, an audit trail was established including raw data (in the form of original lists and recorded interviews), the reduction of data, and its reconstruction into final categories and themes. All analyses were conducted using Microsoft Excel, v.2010. 


\section{Results}

Among the 20 transit operators targeted, 4 chose not to participate. The study sample therefore included 16 of the 20 agencies interviewed for the GAO study. Data were gathered using semi-structured phone interviews with knowledgeable representatives of geographically dispersed transit agencies from nine FTA regions that operate paratransit services. Four agencies interviewed for the current study were also included as full or mini case studies in the 2013 TRB report. Interview respondents included agency managers, paratransit and ADA service directors, and eligibility supervisors. Table 1 summarizes participant demographics by their FTA region and transit agency location.

\section{TABLE 1.}

Transit Agencies Interviewed by FTA Region and Location

\begin{tabular}{|c|l|c|l|}
\hline ID & \multicolumn{1}{|c|}{ Agency } & \multicolumn{1}{|c|}{$\begin{array}{c}\text { FTA } \\
\text { Region }\end{array}$} & \multicolumn{1}{|c|}{ Location } \\
\hline 1 & Access Service Pittsburgh (ACCESS) & 3 & Pittsburgh, PA \\
\hline 2 & Access Services Inc. & 9 & El Monte, CA \\
\hline 3 & Bay Area Rapid Transit (BART) & 9 & Bay Area (SF), CA \\
\hline 4 & Billings Metropolitan Transit (MET) & 8 & Billings, MT \\
\hline 5 & Capital Metro Transit Authority (CapMetro) & 6 & Austin, TX \\
\hline 6 & Dallas Area Rapid Transit (DART) & 6 & Dallas, TX \\
\hline 7 & King County Metro Transit (Metro) & 10 & Seattle, WA \\
\hline 8 & Lane Transit District (LTD) & 10 & Eugene, OR \\
\hline 9 & Metropolitan Council - Metro Mobility & 5 & St. Paul, MN \\
\hline 10 & New Jersey Transit (NJ Transit) & 2 & Newark, NJ \\
\hline 11 & $\begin{array}{l}\text { Niagara Frontier Transportation Authority } \\
\text { (NFTA Metro) }\end{array}$ & 2 & Buffalo, NY \\
\hline 12 & Palm Transit (Palm Tran) & 4 & West Palm Beach, FL \\
\hline 13 & $\begin{array}{l}\text { Toledo Area Regional Transit Authority } \\
\text { (TARTA) }\end{array}$ & 5 & Toledo, OH \\
\hline 14 & Transit Authority of River City (TARC) & 4 & Louisville, KY \\
\hline 15 & Utah Transit Authority (UTA) & 8 & Salt Lake City, UT \\
\hline 16 & Washington Metropolitan Transit Authority & 3 & Washington DC \\
\hline
\end{tabular}

Respondents were asked to describe strategies their respective agencies utilize to improve their eligibility determination processes. Each of the agency representatives interviewed described utilizing at least one of the six best practices identified by Thatcher et al. (2013) during the eligibility determination process (see Table 2). Over half of the agencies $(n=11)$ implemented at least four of the eligibility determination strategies. Four implemented all six practices. Two agencies used only one or two strategies to date, describing implementation costs, limited resources (e.g., funding, time), personnel and facility capacity, and public resistance as barriers to best practice adoption. 
TABLE 2.

Eligibility Determination Strategies by Transit Agency

\begin{tabular}{|c|c|c|c|c|c|c|c|c|c|c|c|c|c|c|c|c|c|}
\hline \multirow{2}{*}{$\begin{array}{l}\text { Eligibility } \\
\text { Determination } \\
\text { Strategy Type }\end{array}$} & \multicolumn{16}{|c|}{ Transit Agency } & \multirow[b]{2}{*}{ Total } \\
\hline & 1 & 2 & 3 & 4 & 5 & 6 & 7 & 8 & 9 & 10 & 11 & 12 & 13 & 14 & 15 & 16 & \\
\hline $\begin{array}{l}\text { In-person interviews } \\
\text { and functional } \\
\text { assessments }\end{array}$ & $\mathrm{x}$ & $\mathrm{x}$ & $x$ & $x$ & $x$ & $\mathrm{x}$ & $\mathrm{X}$ & $\mathrm{X}$ & $\mathrm{X}$ & $\mathrm{X}$ & $\mathrm{x}$ & & $x$ & $x$ & $\mathrm{x}$ & $\mathrm{X}$ & 15 \\
\hline $\begin{array}{l}\text { Measurable and } \\
\text { specific conditions }\end{array}$ & $x$ & $x$ & $\mathrm{x}$ & $x$ & $x$ & & $x$ & $\mathrm{X}$ & & $x$ & & & $x$ & & $x$ & $\mathrm{X}$ & 11 \\
\hline $\begin{array}{l}\text { Efforts to improve } \\
\text { passenger awareness }\end{array}$ & $x$ & $x$ & $x$ & & $x$ & $\mathrm{x}$ & & $x$ & $x$ & $x$ & $x$ & & $x$ & $x$ & & $x$ & 12 \\
\hline $\begin{array}{l}\text { Detailed on-street } \\
\text { assessments }\end{array}$ & $x$ & $x$ & & & $x$ & $x$ & $x$ & $x$ & & $x$ & & $x$ & $x$ & $x$ & $x$ & $x$ & 12 \\
\hline Travel training & & $x$ & & & $\mathrm{x}$ & $\mathrm{X}$ & $X$ & $x$ & $x$ & $x$ & & & $X$ & $X$ & $x$ & $X$ & 11 \\
\hline $\begin{array}{l}\text { Trip-by-trip eligibility } \\
\text { and software }\end{array}$ & $\mathrm{x}$ & & & & $x$ & & $x$ & $x$ & & $\mathrm{x}$ & & & & & $x$ & $x$ & 7 \\
\hline Total & 5 & 5 & 3 & 2 & 6 & 4 & 5 & 6 & 3 & 6 & 2 & 1 & 5 & 4 & 5 & 6 & \\
\hline
\end{tabular}

When grouped together, transit providers reported in-person interviews and functional assessments as the most popular best practice strategy employed during the eligibility process. Fifteen of the 16 agencies implemented this strategy. Agencies described utilizing interviews and functional assessments as a strategy to improve eligibility determination, explaining these tools increase customer education/communication and improve eligibility determination accuracy. A representative from FTA Region 6 stated that adopting this strategy provided "better data and more accurate determinations," "an opportunity for education," and "the ability to refer them to alternative resources and other forms of transportation in service area besides ADA paratransit."

Although all the agencies did not consistently incorporate interviews and functional assessments when determining applicant eligibility, 13 of the 15 agencies adopted in-person interviews as part of their application process. A majority $(n=9)$ conducted them with all applicants. A representative from an agency in FTA Region 5 explained their transition away from paper applications to interviews by saying, "We couldn't really make a best determination on that person. Interviews enable better data and the opportunity for education. This approach provides us the ability to refer them to alternative resources and other forms of transportation in our service area." The remaining six respondents said their agencies conducted interviews with applicants on an as-needed basis, typically to clarify information provided in a written application or documentation from a medical care provider.

Twelve of the 15 agencies used functional assessments to determine the ability of applicants to use fixed route, with only 3 agencies using them consistently with all applicants. A respondent from a paratransit provider in FTA Region 3 described how implementing a functional assessment component contributed to the success of the agency's eligibility determination process:

If the person's disability is primarily physical, the functional assessment is performed by a physical therapist. The physical therapist is conducting a physical, functional assessment. She's taking the person out on a walk to see how they do in the real environment. The decision was made to add these kinds of functional assessments, to increase the reliability and the accuracy of the decisions. 
A majority of the 12 agencies using functional assessments $(n=9)$ conducted them with only some of their applicants based on an applicant's functional mobility. An interviewee from FTA Region 9 explained that "functional assessments are used if we are going to deny someone or grant them conditional eligibility, because it is preferred that an occupational therapist verifies this [decision] for credibility."

Many of the 12 agencies conducting functional assessments utilized a combination of indoor and outdoor testing to improve the accuracy of eligibility determinations, which included asking applicants to navigate a mockup fixed route bus, ADA and non-ADA compliant ramps, uneven services, a simulated transit trip, and physical barriers in a community setting. Agencies frequently hire dedicated personnel to conduct assessments or collaborate with local universities to obtain support from physical, occupational, and rehabilitation therapy students. Hiring dedicated personnel or collaborating with other organizations that provide this expertise contributes to improved accuracy of eligibility determinations. A staff member from FTA Region 9 explained, "We contracted with [a local university] because they have experts there on a wide range of specialties who can then be matched to specific riders (e.g., occupational therapists)." Additionally, some agencies use other assessment tools, such as the Functional Assessment of Cognitive Transit Skills (FACTS) test or Allen Assessment, to gain information on an applicant's cognitive ability.

Several agencies described challenges they encountered when implementing interviews and functional assessments, such as ensuring the accuracy and consistency of determinations, addressing the high volume of applicants, and confronting customer appeals. Those who did not currently utilize one or both methods of assessment cited cost, increasing passenger applications, and a lack of resources (e.g., facility, staffing) as barriers to adopting this practice. One respondent from an agency in FTA Region 4 explained:

No test. Nothing of that sort....Again, most of the people that qualify probably only one in five actually are regular users of the service. It just did not make sense to hire or to staff it. Financially, we're still looking at doing that, but we have never got to that. There was more of a financial decision not to.

Transit agencies also grant conditional eligibility to improve the accuracy of eligibility decisions and encourage passengers to take fixed route when feasible and appropriate. Eleven of the 16 agencies currently use measurable and specific conditions (i.e., environmental barriers, functional ability) as a strategy to improve eligibility determinations when granting conditional eligibility for applicants.

Other agencies experienced both political and operational challenges that hindered their capacity to determine conditional eligibility. An interviewee from FTA Region 4 explained how political challenges prohibited their agency from adopting this practice: "We'd love to do conditional eligibility, but just can't, given our environment. We're a very customer-driven county. Customers are very vocal and the county rescinded changes within 9 days in response to customer complaints." Even the agencies that adopted this practice described similar implementation challenges, including political and community pushback and the difficulty in implementing and enforcing this strategy due to funding, software deficits, scheduling challenges, and cost. To overcome community pushback, a representative from a paratransit provider in FTA Region 10 described agency efforts to educate customers, and more broadly members of the disability community, that the goal of determining conditions was to determine people's ability to utilize public transit, rather than limiting service on paratransit.

When probed about the implementation of conditional eligibility in service delivery, many agencies $(n=11)$ pointed to weather-related conditions as a primary reason for granting conditional eligibility for individual trip requests. Interviewees commonly reported that granting conditional eligibility based on weather-related 
conditions is typically straightforward to determine, easy to uphold, and equally impactful. A representative from a paratransit agency in FTA Region 3 said:

Our most common conditionals are extreme heat. Extreme cold. People's ability to tolerate and travel outside, wait at a bus stop, etc. If it's over 80 degrees or under 40 degrees, if there is snow or ice on the ground, that obviously limits people who are in a mobility device, or have fragile ambulation. Dark is another common one that we use. If someone can see well during daylight but their vision is poor at night, we'll make it conditional that they can use paratransit at night.

However, some agencies struggle to apply weather-related conditions on a trip-by-trip basis. Instead, some adopt a seasonal eligibility due to software and personnel limitations. An interviewee from FTA Region 3 explained:

Weather ranges hugely in the winter. We divide the year into two pieces, Labor Day-Memorial Day ("winter") and Memorial Day-Labor Day ("summer"), to determine weather-related eligibility. It is easier for reservationists and more cost effective than trip-by-trip weather determination because weatherrelated eligibility is difficult to determine for individual applicant.

Even when transit agencies utilize conditional eligibility to reduce paratransit trips, they often encounter implementation challenges. For example, 5 of the 12 agencies granting conditional eligibility to customers are not able to apply identified conditions to scheduling decisions on a trip-by-trip basis. An interviewee from FTA Region 6 stated, "We can't enforce conditions unless looking and enforcing by trip. We currently do not have the ability to enforce trip-by-trip scheduling." Four of these five agencies pointed to software limitations as the largest barrier to implementing trip-by-trip determinations. An interviewee from a transit agency in FTA Region 8 described agency efforts to adapt software to support trip-by-trip screening:

Schedulers have to look up to see what the rider's conditions of eligibility are. We only provide transportation within three quarters of a mile of fixed route. So, if they live in an area where we don't have the frequency of service, the schedulers might create a pop up that says, "This person is only eligible to ride during these times." We create little notes in there that pop up when a scheduler is scheduling some person's ride, it's attached to that person, and so any scheduler can look to see this information.

In other efforts to improve eligibility determinations, transit agencies used detailed on-street assessments to learn more about barriers in the built environment that lead individuals to use paratransit. Twelve of the agencies interviewed integrated detailed on-street assessments in various phases of their determination process, such as when conducting in-person functional assessments, determining the eligibility of trip requests, and investigating customer appeals. Agencies used various modes to assess and track built environment data, including carrying out real-world assessments with in-house checklists or environmental audits, identifying and tracking path-of-travel barriers using Google Earth and GIS, and addressing customer-reported barriers through travel training assessments. One interviewee from a paratransit provider in FTA Region 6 described an agency partnership with the city to collect data about environmental barriers and share information to facilitate public infrastructure improvements:

We hired a lead mobility specialist, who is able to tag along to the city's assessment efforts. This helps to address accessibility barriers. We feed information [for] scheduling trips and also city improvements. It is about having the right people in place with the right technical knowledge.

A respondent from FTA Region 8 described their efforts to use informal collaborations with other municipal departments to share information about environmental barriers. She explained, "I am involved with several 
committees and try to share the information about environmental barriers that we collect as part of our assessments. We try to work as a city in our planning...."

Even though the majority of transit agencies interviewed conducted street assessments, only a small number $(n=4)$ described successfully sharing information collected about environmental barriers with municipal offices to facilitate public infrastructure improvements. The representative from a transit agency in FTA Region 3 shared the challenge her agency encountered when attempting to implement this strategy:

We track the barrier that created eligibility for all of the conditionally eligible trips. We had this notion at one time that we were going to share that information with mini-support government, so that they could improve the pedestrian environment. We tried that for years...The only thing that we do now is try to keep track of which bus stops are not accessible. The answer is we tried and no one was listening.

Transit agencies described the use of customer outreach and travel training as successful strategies to encourage more fixed route ridership amongst paratransit users. Twelve agencies reported using outreach efforts to improve passenger awareness regarding conditions of eligibility and other available accessible transportation options. These efforts included informing individual customers about the implications of their conditional eligibility through letters and phone calls. One representative from a paratransit provider in FTA Region 10 explained that they incorporated customer education directly into the agency's eligibility determination process:

We do this as part of our interviews...discuss travel training and other transportation options to help the applicant coordinate multiple services. We see it as an integral part of [the] assessment process, and want to get people to use fixed route so we give options at the time of the interview. The applicant can have individual challenges but our transportation coordinator is able to help with this. It is easier to do in-person.

Despite some agencies' successes utilizing outreach, other agencies objected to utilizing these practices to encourage greater use of fixed route. An interviewee from an FTA Region 4 agency who had not implemented this strategy, and did not support sharing information on alternative transportation options with paratransit eligible individuals, equated doing so as "pushing them off onto fixed route." Others encountered challenges when trying to implement these strategies. For example, an interviewee from FTA Region 8 said her agency had utilized customer outreach to educate passengers about other transportation options, but stopped due to resource and funding constraints and feelings that customers did not use the provided information:

We previously sent out routes and schedules in the area and had videos about fixed route service, but riders didn't really use them. Now we just wait for them to call in. If riders have additional questions, we transfer them to the mobility center or customer care department.

More than half $(n=11)$ of the agencies offer travel training as part of their eligibility practices to support the use of fixed route options. Agencies provide travel training to individual applicants who voluntarily seek out this support and to prospective applicants through community trainings. A representative located in FTA Region 3 described reframing the portrayal of fixed route as part of an agency approach to promote travel training, explaining, "We stress [the] opportunities fixed route service provides to ride independently, [no need to] make reservations, and give yourself a pay raise for free. We put marketing posters in the train stations and bus stops and put ads in the paper." Additional innovative approaches to fixed route travel training include stressing the incentives of fixed route transportation, offering unlimited and one-on-one travel training to customers on an ongoing basis, and tracking customer success after training completion. An interviewee from a provider in FTA Region 2 described how the agency incoporated various innovative approaches when establishing their travel training program: 
Travel instructors have experience working with people of various disabilities...They spend a day traveling throughout different transportation, learning about different services. Individuals participating in the training are given extensive, unlimited travel instruction and then evaluated. The program addresses what happens if the bus doesn't show up and how to advocate for themselves. When they graduate, they are given a free one month pass on their mode of choice. We go through great efforts to make sure customers feel comfortable, and do not want customers to feel that they are getting pushed onto fixed route. Eligibility for paratransit is not effected by travel training.

Five transit agencies interviewed do not currently offer formal in-house travel training programs. Of those five, two previously offered it but discontinued the service due to implementation challenges. A representative from a paratransit provider in FTA Region 4 said, "The process has stalled. Our marketing person used to provide travel training...but our marketing department went down from 8 to 4, so the travel training ceased." Additionally, some agencies may not provide training directly, but refer applicants to training resources within the community during the eligibility assessment. An interviewee from an agency in FTA Region 9 explained:

The county provides funding for travel training, so we refer people to it. Some people are given temporary eligibility and the recommendation to go to get travel training, but we can't require it. When eligibility runs out, customers are asked if they've had travel training and are then given information during their interview.

\section{Discussion}

The current study addressed two gaps in the paratransit literature by investigating how transit agencies utilize best practice strategies when determining eligibility in daily operations and exploring factors that contribute to implementation successes and challenges. The findings indicate that most transit agencies in the sample have incorporated multiple best practice eligibility strategies as part of department-wide changes in paratransit operations. For example, the analysis revealed that agencies granting conditional eligibility often make other changes to their assessment procedures, such as using in-person interviews and functional assessments and conducting detailed on-street assessments to determine path-of-travel barriers. This reinforces the importance of addressing the needs of people with disabilities throughout the various aspects of paratransit operations. Thatcher et al. (2013) contend that a system-wide policy on accessibility and services for persons with disabilities is critical to the success of individual departmental changes, such as the adoption of eligibility determination best practices.

As part of their paratransit eligibility process, many agencies incorporated practices that focus on identifying and enhancing a customer's ability to use fixed route and other transportation options available, rather than focusing solely on their limitations. Interviews with agencies revealed that departmental practices focusing on ability to use fixed route are not always limited to assessment procedures or criteria for determining eligibility for service. Several agencies incorporated this philosophy as a way to rebrand the messaging of public outreach campaigns, informational material for customers, and travel training to describe personal benefits or "upgrades" to fixed route service, such as cost savings, scheduling freedom, and personal autonomy.

Interview findings also suggest that adopting an eligibility determination strategy in isolation of other practices may pose implementation challenges. This is particularly true for conditional eligibility and the interdependence of this strategy with path-of-travel assessments and trip-by-trip scheduling. While many agencies currently grant some form of conditional eligibility to paratransit customers, not all have the operational practices or infrastructure to meaningfully identify paratransit eligible customer trips or consistently apply it to trip scheduling. For instance, some agencies grant eligibility for weather-related conditions such as temperature. 
However, not all agencies assess temperature on a daily basis, but rather enforce this condition seasonally (e.g., summer/winter). Other agencies use more specific criteria related to distance and path-of-travel barriers for assessing customer ability to use fixed route, but do not have the software or personnel to determine the eligibility of specific trip requests of individual customers on a regular basis. Agencies successfully using conditional eligibility describe an implementation process that is inexpensive and incremental, including modifying existing software to meet needs and creating a community database of path-of-travel barriers based on the assessment of individual customers.

Agencies may be able to overcome implementation challenges by recognizing their own departmental constraints and limitations and collaborating with other departments and outside organizations to overcome these challenges. Successful collaborations shared by interview respondents included formal, large-scale partnerships and informal involvement of individual staff members. For example, several agencies reported problems when trying to share path-of-travel barriers with other departments responsible for municipal infrastructure improvements. Agencies able to overcome this challenge did so through staff participation in local public rights-of-way committee meetings, collaboration with transportation planners, and a formal partnership with city infrastructure assessment efforts. Other agencies collaborated with university rehabilitation science programs and professionals to coordinate functional assessments and travel training efforts to address personnel and budget constraints.

This study had several principal limitations. First, qualitative data analysis is inherently prone to biases during data analysis. To mitigate this challenge, the current study utilized three data coders representing diverse discipline backgrounds and professional experiences. Second, the interview sample was potentially biased because all contacts were recruited from a previous study sample. However the sampling frame (i.e., range of transit agencies and geographic dispersion) of this study was purposefully chosen so that data would reflect the experiences of diverse municipalities to diminish this potential bias. Third, interviewees may have felt reluctant to disclose attributes of their paratransit programs or personnel that could be negatively construed, which is a risk with any self-reflective interview process. Fourth, the small sample size limits the generalizability of the results.

While this study expanded upon existing case study research, additional research is still needed. A national survey of transit agencies would establish a "state-of-practice" snapshot regarding the implementation and impact of eligibility best practices across the United States. The current study's findings yielded numerous useful insights that can inform such a survey with meaningful questions and practical response options that would support its success on a large scale. Another area for further study includes riders' perspectives on improvements to paratransit services. Future research should document rider feedback after changes to the eligibility determination process are implemented and further explore factors that influence their transportation decision making.

\section{Conclusion}

Previous research examining eligibility determination best practices in complementary ADA paratransit has been limited to case study and qualitative approaches. This was the first study to report systematic data capture and analysis of the implementation of eligibility determination best practices for complementary ADA paratransit service. Interviews with paratransit departments identified how and the extent to which a diverse sample of transit agencies implement best practice strategies, and identified operational factors that contribute to implementation successes and challenges. The findings call attention to the need for transit agencies to develop long-term departmental-scale plans when adopting changes to eligibility assessment procedures. To 
overcome common challenges, such as public pushback and resource constraints, study findings suggest that agencies should consider addressing the customer benefits of fixed route transit in public outreach campaigns, customer information, and travel training programs, and by developing collaborations with other departments, municipal offices, and community organizations. These findings also highlight the need for future research to quantify the impact of best practices strategies and document implementation feedback from the perspective of paratransit riders.

\section{Acknowledgments}

The contents of this paper were developed under a grant from the National Institute on Disability, Independent Living, and Rehabilitation Research (NIDILRR grant number 90RE5011-01-00). NIDILRR is a center within the Administration for Community Living (ACL), Department of Health and Human Services (HHS). The contents of this paper do not necessarily represent the policy of NIDILRR, ACL, HHS, and readers should not assume endorsement by the federal government.

\section{References}

Cross, D. 2007. "ADA Paratransit Eligibility Models: Comparing the Options." Presentation at the 2006 Bus \& Paratransit Conference, American Public Transportation Association, Washington, DC.

GAO (US Government Accountability Office). 2012. ADA Paratransit Services: Demand Has Increased, but Little is Known about Compliance. GAO-13-17. Washington, DC. https://www.gao.gov/assets/660/650079.pdf.

Gupta, D., H. Chen, L. A. Miller, and F. Surya. 2010. "Improving the efficiency of demand responsive paratransit services." Transportation Research Part A: Policy and Practice 44 (4): 201-217.

Henning, A. 2007. Public Transportation Providers' Obligations under the Americans with Disabilities Act. Congressional Research Service. http://assets.opencrs.com/rpts/RS22676_20070611.pdf. Accessed July 17, 2013.

Hoesch, K. and E. Roszner. 1995. "A Model Process for Determining Paratransit Eligibility. "Presentation at the 7th International Conference on Mobility and Transport for Elderly and Disabled People, Transportation Research Board, Washington, DC.

Koffman, D., R. Weiner, A. Pfeiffer, and S. Chapman. 2010. Funding the Public Transportation Needs of an Aging Population. American Public Transportation Association. San Francisco: Nelson/Nygaard Consulting Associates.

Mathias, R. G., and R. H. Thatcher. 2002. ADA Complementary Paratransit: A Decade of Innovation. Washington, DC: Easter Seals Project ACTION.

Morgan, D. L. 1997. Focus Groups as Qualitative Research, Second Edition. Thousand Oaks, CA: Sage Publications, Inc.

National Academies of Sciences, Engineering, and Medicine. 2007. Improving ADA Complementary Paratransit Demand Estimation. TCRP Report 119. Washington, DC: The National Academies Press. doi:10.17226/23146.

NCD (National Council on Disability). 2005. The Current State of Transportation for People with Disabilities in the United States. Washington, DC. 
Rogers, E., and D. Wiemiller. 2006. "Sustainable ADA Compliance: Meeting Paratransit Demand Through Growth Management Strategies." Presentation at the 2006 Bus \& Paratransit Conference, American Public Transportation Association, Washington, DC.

Sapper, D., J. Goodwill, and H. Carapella. 2009. Impacts of More Rigorous ADA Paratransit Eligibility Assessments on Riders with Disabilities. Revised Draft Final Report, Project \#BD549-44. National Center for Transit Research, Center for Urban Transportation Research, University of South Florida, Tampa, FL.

Thatcher, R., C. Ferris, D. Chia, J. Purdy, B. Ellis, B. Hamby, J. Quan, and M. Golden. 2013. Strategy Guide to Enable and Promote the Use of Fixed-Route Transit by People with Disabilities. TCRP Report 163. Washington, DC: Transportation Research Board.

Weiner, R. 2007. "Paratransit Eligibility Screening Has Become a Critical Tool in Managing ADA Paratransit Demand." 11th International Conference on Mobility and Transport for Elderly and Disabled People (TRANSED), Montreal, Canada.

Weiner, R. 1998. ADA Paratransit Eligibility Certification Practices. TCRP Synthesis 30, Transportation Research Board. Washington, DC: National Academy Press.

Welch, B., and T. Dubost. 2005. "Controlling ADA Paratransit Costs with In-Person Eligibility Assessment." Paper presented at the 2005 Bus \& Paratransit Conference, American Public Transportation Association, Washington, DC.

\section{About the Authors}

Molly E. Ranahan, MUP (ranahan@buffalo.edu) is a PhD candidate in the Department of Urban and Regional Planning at the University at Buffalo and a research analyst for the County of Erie Department of Senior Services.

Jordana L. Maisel, PhD, MUP (jlmaisel@buffalo.edu) is the director of research activities for the Center for Inclusive Design and Environmental Access and a research assistant professor in the School of Architecture and Planning at the University at Buffalo.

James A. Lenker, PhD, OTR/L (lenker@buffalo.edu) is an associate professor in the Rehabilitation Science Department of the School of Public Health \& Health Professions at the University at Buffalo and the program director for the Advanced Graduate Certificate Program in Assistive \& Rehabilitation Technology. 